\title{
КРИТЕРИИ ОЦЕНИВАНИЯ ДЕТСКИХ РАБОТ ПО ОБРАЗНОМУ РЕШЕНИЮ ПОРТРЕТА НА УРОКАХ ИЗОБРАЗИТЕЛЬНОГО ИСКУССТВА
}

\author{
Горюнова Снежана Вадимовна \\ магистрант \\ Научный руководитель: Полынская И.Н. \\ доктор пед. наук, профессор кафедры ИЗО \\ ФГБОУ ВО «Нижневартовский государственный \\ университет», г. Нижневартовск
}

\begin{abstract}
Аннотация: В статье рассмотрены различные подходы по изучению закономерностей изобразительной деятельности детей, изучены существующие системы критериев оценивания детских рисунков. В результате исследования разработаны и предложены критерии оценивания детских работ по образному решению портрета на уроках изобразительного искусства.

Ключевые слова: Изобразительная деятельность, детское творчество, образное решение, критерии оценивания, художественно-образное решение, художественно-выразительные качества композиции, художественновыразительные качества цвета.

\section{EVALUATION CRITERIA OF CHILDREN'S WORKS FOR THE IMAGINATIVE SOLUTION OF A PORTRAIT IN FINE ART LESSONS}

\section{Goryunova Snezhana Vadimovna Polynskaya Irina Nikolaevna}

Abstract: The article considers various approaches to studying the patterns of children's pictorial activity, and examines the existing systems of criteria for of criteria for evaluating children's drawings. As a result of the research, the evaluation criteria of children's works for the imaginative solution of a portrait in fine art lessons were developed and proposed.
\end{abstract}




\section{НАУКА, ОБЩЕСТВО, КУЛЬТУРА: ПРОБЛЕМЫ

Key words: Pictorial activity, children's creativity, imaginative solution, evaluation criteria, artistic-imaginative solution, artistic-expressive qualities of composition, artistic-expressive qualities of color.

Детский рисунок это не только результат реализации поставленной педагогом задачи, но и продукт собственного творчества.

Однако с точки зрения педагогической значимости, изобразительная деятельность детей на уроках изобразительного искусства требует постоянного анализа, координации и контроля, позволяющего оценивать качество и результативность учебного процесса, а также мотивировать личностное развитие учащихся. В противном случае, детское творчество может пойти по пути «хаотичного развития», которое приведет к упущению или искажению основ изобразительной грамоты и, что важнее, к карикатурному характеру создания художественного образа в детском рисунке.

Исследование закономерностей изобразительной деятельности детей, анализ и оценивание детских рисунков стало приоритетным направлением научной мысли начала XX века и проводилось такими учеными, как А.В. Бакушинский, Г. Кершенштейнер, К. Лампрехт, К. Риччи.

Они полностью переосмыслили природу детского творчества: их идеалистические взгляды на детский рисунок как высшее произведение искусства опирались на биогенетическую теорию спонтанного развития. Однако такой подход не позволяет выявить сущность самобытности детского творчества, а отсутствие активного руководства со стороны отвергает саму концепцию преемственности, в частности, преемственности основ реалистического рисунка. Как отмечает С.Е. Игнатьев: «Таким образом, рисунки детей часто оставались примитивными» [2, с. 12]

Вопросом изучения детского изобразительного творчества в середине 30 х гг. занимался советский психолог и педолог Н. А. Рыбников. В его работе «Детские рисунки и их значение» (1926 г.) были собраны и проанализированы исследования зарубежных и отечественных ученых. Автором приведена схема квалификации детских рисунков, включающая такие позиции, как: «отдельные предметы (отдельные предметы, фон, объединенные группы рисунков); «композиция», «пространство», «движение», «цвет», «фактура». Согласно Н.А. Рыбникову данная схема является общей для анализа любого детского рисунка. 


\section{НАУКА, ОБЩЕСТВО, КУЛЬТУРА: ПРОБЛЕМЫ И ПЕРСПЕКТИВЫ ВЗАИМОДЕЙСТВИЯ В СОВРЕМЕННОМ МИРЕ}

[5, с. 12-15]. Многие из предложенных квалификаций активно используются специалистами и в настоящее время.

Заслуживают внимания и более поздние работы в области исследования детской изобразительной деятельности. Ряд ученых (К.М.Багдасарян, Н.А. Ветлугина, Е.И. Игнатьев, Т.С. Комарова, В.С. Кузин, В.С. Мухина, Н.П. Сакулина, Е.А. Флерина, Е.В. Шорохов) работали над определением системы критериев, отражающих многообразие проявлений детей в изобразительной деятельности. Данные критерии отражали такие стороны детского рисунка, как эмоциональность, содержательность, различные качественные показатели. Система критериев приобретает признаки целостности, рациональности и большей объективности.

Существенный вклад в развитие системы оценивания детских рисунков внес С.Е. Игнатьев. В работе «Закономерности изобразительной деятельности детей» (2007 г.) автор предлагает свой вариант критериев оценки детских работ. «С. Е. Игнатьев рассматривает линию, цвет, объемные построения, художественный образ, композиционно-пространственные построения в детском рисунке и его возрастную эволюцию» [3, с. 177]. Исследования С.Е. Игнатьева представляют собой особую ценность по полноте и содержанию проделанной работы в области изучения детского творчества и позволяют адаптировать и применить предложенные критерии на конкретном уроке (согласно изучаемой теме).

В настоящее время исследователи детского художественного творчества продолжают работу по исследованию и разработке собственных критериев оценки детского рисунка. Данная тенденция объясняется разнообразием и спецификой изучаемых тем на уроках изобразительного искусства, возрастными и индивидуальными особенностями учащихся и, следовательно, необходимостью использования нешаблонных подходов к оценке результатов детского творчества.

Так в работе И.Н. Полынской (2009) автором определена система критериев, каждый компонент которой наиболее полно характеризует уровень сформированности интереса к исследуемой теме и дает объективную оценку результата практической деятельности учащихся. Критерии оценивания распределены по следующим блокам:

1. «Художественно-образное решение изображения»;

2. «Художественно выразительные качества композиции»; 


\section{НАУКА, ОБЩЕСТВО, КУЛЬТУРА: ПРОБЛЕМЫ

3. «Цвет в рисунках учащихся»;

Каждый из блоков включает перечень позиций, разработанных в соответствие со спецификой темы исследования.

«Данные критерии демонстрируют имеющиеся в методике обучения детей изобразительному искусству педагогические взгляды и художественные приемы, которые отвечает основам обучения реалистического рисования школьников и способствуют формированию у них интереса к национальной культуре» [4, с. 165-171].

Опираюсь на достижения ученых, мы разработали собственные критерии оценки детского рисунка. Предлагаемая система критериев включает в себя как общие изобразительные аспекты, так и отвечающие особенностям содержания темы нашего исследования «Образное решение портрета учащимися 3-4 классов на уроках изобразительного искусства».

Данная система критериев отвечает требованиям образовательной системы и, на наш взгляд, учитывает возрастные особенности и способности изобразительной деятельности учащихся общеобразовательной школы.

Представленная в работе система критериев для упорядоченности и простоты восприятия была разделена на блоки.

\section{Первый блок «Художественно-образное решение изображения».} Данный блок определяет уровень сформированности образного мышления учащихся: умение не только воспроизводить, но и создавать яркие, «живые» и оригинальные образы согласно художественному замыслу.

Позиция № 1. «Оригинальность художественного замысла».

Позиция № 2. «Яркость и выразительность художественного образа».

Позиция № 3.«Передача характера, эмочионального состояния изображаемого»:

- с помощью мимики, позы, жестов;

- средствами художественной выразительности.

Позиция № 4. «Передача портретного сходства».

Позиция № 5. «Детализация образа»: проработка прически, одежды, аксессуаров для раскрытия художественного замысла.

Портрет, как и любой другой жанр искусства, предполагает создание «колоритного» художественного образа, наполненного богатством содержания. Следовательно, этот блок представляет особую психолого-педагогическую ценность и занимает первое место в общей системе оценки детского рисунка. 


\section{НАУКА, ОБЩЕСТВО, КУЛЬТУРА: ПРОБЛЕМЫ \\ И ПЕРСПЕКТИВЫ ВЗАИМОДЕЙСТВИЯ В СОВРЕМЕННОМ МИРЕ}

Второй блок «Художественно-выразительные качества композиции (композиционное решение изображения») оценивает художественные способности учащихся в грамотном композиционно-пространственном построении изображения и подчинении его художественному замыслу.

Позиция №1. «Выбор формата и размера изображения»:

- формат: горизонтальный, вертикальный;

- размер: мелкий, нормальный, крупный;

Позиция № 2. «Уравновешенность и целостность композиции (гармоничное заполнение поверхности листа)» цветовыми пятнами, элементами композиции.

Позиция № 3. «Выделение ведущего элемента композищии» цветом, тоном, размером, степенью детализации.

Позиция № 4. «Динамичность изображения согласно художественному замыслу». Динамичность (передача движения) может быть выражена линиями, цветовыми пятнами, позой, жестом, положением головы, мимикой. Умение передать движение в портрете учащимся обусловлена не только наличием смысловой связи с художественным замыслом, но и уровнем сформированности его эмоциональной отзывчивости, которая выражается в способности «воспринимать, идентифицировать и оценивать эмоциональное состояние (содержание)» портретируемого [1, с. 75].

Позиция № 5. «Объемно-пространственное построение изображения»:

- связь фона с изображением (портретируемого). Фон должен раскрывать характер, передавать настроение портретируемого, т.е. «играть» на раскрытие художественного замысла.

Третий блок. «Художественно-выразительные качества цвета (цветовое решение изображения)».

Позиция № 1. «Живописность работы»:

- сложность цвета и цветовых отношений: локальные цвета, сочетание локальных и сложных цветов, преобладание сложных цветов;

- цветовая гармония в портрете: выделяют монохромную и контрастную гармонию; здесь важно грамотное использование цветовых отношений в определенном колорите (теплом или холодном, светлом или темном, с доминированием какого-либо цвета). 


\section{НАУКА, ОБЩЕСТВО, КУЛЬТУРА: ПРОБЛЕМЫ \\ И ПЕРСПЕКТИВЫ ВЗАИМОДЕЙСТВИЯ В СОВРЕМЕННОМ МИРЕ}

Позиция № 2. «Соответствие цветового решения художественному замыслу». Данная позиция определяет умение использовать выразительные возможности цвета для раскрытия характера, передачи настроения в портрете.

Каждый из блоков и входящие в него позиции характеризуются по уровням: «низкий уровень», «средний уровень», «высокий уровень», каждому из которых присваивается оценка: «3», «4», «5», соответственно.

Предлагаемую систему критериев (табл. 1) рекомендуется использовать для оценивания детских работ по образному решению портрета.

Таблица 1

\section{Критерии оценивания работ учащихся по образному решению портрета}

\begin{tabular}{|c|c|c|c|}
\hline \multirow{2}{*}{ Параметры } & \multicolumn{3}{|l|}{ Уровни } \\
\hline & Низкий уровень & Средний уровень & Высокий Уровень \\
\hline \multicolumn{4}{|c|}{ Блок 1. Художественно-образное решение изображения } \\
\hline $\begin{array}{l}\text { 1. Оригинальность } \\
\text { художественного } \\
\text { замысла }\end{array}$ & $\begin{array}{l}\text { Тривиальное } \\
\text { образное решение; } \\
\text { отсутствие } \\
\text { индивидуального } \\
\text { подхода. } \\
\text { Шаблонный, } \\
\text { предметный } \\
\text { замысел. }\end{array}$ & $\begin{array}{l}\text { Частичная } \\
\text { оригинальность в } \\
\text { изображении } \\
\text { художественного } \\
\text { образа; проявление } \\
\text { индивидуального } \\
\text { подхода. } \\
\text { Вариативный, } \\
\text { гибкий замысел }\end{array}$ & $\begin{array}{l}\text { Оригинальное } \\
\text { образное решение; } \\
\text { изображение образа } \\
\text { по личному } \\
\text { художественному } \\
\text { представлению и } \\
\text { отношению. } \\
\text { Оригинальный, } \\
\text { ассоциативный, } \\
\text { замысел }\end{array}$ \\
\hline $\begin{array}{l}\text { 2. Яркость и } \\
\text { выразительность } \\
\text { художественного } \\
\text { образа }\end{array}$ & $\begin{array}{l}\text { Слабо выраженная } \\
\text { идейно- } \\
\text { эмоциональная } \\
\text { насыщенность - } \\
\text { образ «блеклый, не } \\
\text { выразительный }\end{array}$ & $\begin{array}{l}\text { Недостаточная } \\
\text { идейно- } \\
\text { эмоциональная } \\
\text { насыщенность } \\
\text { образа - образ } \\
\text { интересный, но } \\
\text { требует большей } \\
\text { выразительности }\end{array}$ & $\begin{array}{l}\text { Сильная идейно- } \\
\text { эмоциональная } \\
\text { насыщенность } \\
\text { образа - образ } \\
\text { яркий и } \\
\text { выразительный }\end{array}$ \\
\hline $\begin{array}{l}\text { 3. Передача } \\
\text { характера, } \\
\text { эмоционального } \\
\text { состояния } \\
\text { изображаемого }\end{array}$ & $\begin{array}{l}\text { Характер и эмоции } \\
\text { слабо выражены } \\
\text { или же не } \\
\text { соответствуют } \\
\text { художественному } \\
\text { замыслу. } \\
\text { Не умеет } \\
\text { передавать } \\
\text { характер, } \\
\text { настроение с } \\
\text { помощью а) } \\
\text { мимики, позы, }\end{array}$ & $\begin{array}{l}\text { Характер и эмоции } \\
\text { угадываются, но не } \\
\text { полностью } \\
\text { отражают } \\
\text { художественный } \\
\text { замысел. } \\
\text { Неуверенно } \\
\text { передает характер, } \\
\text { настроение с } \\
\text { помощью а) } \\
\text { мимики, позы, } \\
\text { жестов; б) средств }\end{array}$ & $\begin{array}{l}\text { Характер и эмоции } \\
\text { ярко выражены и } \\
\text { полностью } \\
\text { соответствую } \\
\text { художественному } \\
\text { замыслу. } \\
\text { Умеет передавать } \\
\text { характер, } \\
\text { настроение с } \\
\text { помощью а) } \\
\text { мимики, позы, } \\
\text { жестов; б) средств }\end{array}$ \\
\hline
\end{tabular}




\section{НАУКА, ОБЩЕСТВО, КУЛЬТУРА: ПРОБЛЕМЫ И ПЕРСПЕКТИВЫ ВЗАИМОДЕЙСТВИЯ В СОВРЕМЕННОМ МИРЕ}

\begin{tabular}{|c|c|c|c|}
\hline & $\begin{array}{l}\text { жестов; б) средств } \\
\text { художественной } \\
\text { выразительности }\end{array}$ & $\begin{array}{l}\text { художественной } \\
\text { выразительности }\end{array}$ & $\begin{array}{l}\text { художественной } \\
\text { выразительности }\end{array}$ \\
\hline $\begin{array}{l}\text { 4. Передача } \\
\text { портретного } \\
\text { сходства }\end{array}$ & $\begin{array}{l}\text { Невыраженные } \\
\text { характерные черты } \\
\text { внешности } \\
\text { изображаемого; не } \\
\text { умеет выделить } \\
\text { главное (особенное) } \\
\text { во внешности }\end{array}$ & $\begin{array}{l}\text { Выраженные } \\
\text { характерные черты } \\
\text { внешности } \\
\text { изображаемого; но } \\
\text { главное (особенное) } \\
\text { во внешности не } \\
\text { выделено или } \\
\text { выделено } \\
\text { неправильно }\end{array}$ & $\begin{array}{l}\text { Выраженные } \\
\text { характерные черты } \\
\text { внешности } \\
\text { изображаемого; } \\
\text { главное (особенное) } \\
\text { во внешности очень } \\
\text { точно выделено, ярко } \\
\text { выражена } \\
\text { индивидуальность } \\
\text { изображаемого }\end{array}$ \\
\hline $\begin{array}{l}\text { 5. Детализация } \\
\text { образа }\end{array}$ & $\begin{array}{l}\text { Слабая } \\
\text { детализация } \\
\text { образа: прическа, } \\
\text { одежда, аксессуары } \\
\text { не проработаны, не } \\
\text { отражают } \\
\text { художественный } \\
\text { замысел }\end{array}$ & $\begin{array}{l}\text { Умеренная } \\
\text { детализация } \\
\text { образа: } \\
\text { прическа, одежда, } \\
\text { аксессуары хорошо } \\
\text { проработаны, но не } \\
\text { полностью } \\
\text { отражают } \\
\text { художественный } \\
\text { замысел }\end{array}$ & $\begin{array}{l}\text { Грамотная } \\
\text { детализация образа: } \\
\text { прическа, одежда, } \\
\text { аксессуары } \\
\text { лаконично } \\
\text { подобраны и } \\
\text { хорошо } \\
\text { проработаны и } \\
\text { полностью } \\
\text { отражают } \\
\text { художественный } \\
\text { замысел }\end{array}$ \\
\hline \multicolumn{4}{|c|}{ Блок 2. Художественно-выразительные качества композиции } \\
\hline $\begin{array}{l}\text { 1. Выбор формата } \\
\text { и размера } \\
\text { изображения }\end{array}$ & $\begin{array}{l}\text { Формат выбран } \\
\text { неверно, размер } \\
\text { изображении или } \\
\text { мелкий, или, } \\
\text { напротив, крупный }\end{array}$ & $\begin{array}{l}\text { Формат выбран } \\
\text { верно, но размер } \\
\text { изображения } \\
\text { немного меньше } \\
\text { или же крупнее } \\
\text { необходимого } \\
\end{array}$ & $\begin{array}{l}\text { Формат и размер } \\
\text { выбраны верно }\end{array}$ \\
\hline $\begin{array}{l}2 . \\
\text { Уравновешенност } \\
\text { ь и целостность } \\
\text { композиции }\end{array}$ & $\begin{array}{l}\text { Композиция не } \\
\text { уравновешена . } \\
\text { Дробность } \\
\text { композиционного } \\
\text { строя. }\end{array}$ & $\begin{array}{l}\text { Есть стремление к } \\
\text { уравновешиванию } \\
\text { композиции. } \\
\text { Отмечается } \\
\text { небольшая } \\
\text { дробность } \\
\text { композиционного } \\
\text { строя }\end{array}$ & $\begin{array}{l}\text { Композиция } \\
\text { уравновешена } \\
\text { цветовыми пятнами, } \\
\text { элементами } \\
\text { композиции. } \\
\text { Целостность } \\
\text { композиционного } \\
\text { строя }\end{array}$ \\
\hline $\begin{array}{l}\text { 3. Выделение } \\
\text { ведущего } \\
\text { элемента } \\
\text { композиции }\end{array}$ & $\begin{array}{l}\text { Ведущий элемент } \\
\text { не выделен }\end{array}$ & $\begin{array}{l}\text { Ведущий элемент } \\
\text { определен, но } \\
\text { «спорит» с другим } \\
\text { равнозначным } \\
\text { элементом }\end{array}$ & $\begin{array}{l}\text { Ведущий элемент } \\
\text { выделен }\end{array}$ \\
\hline $\begin{array}{l}\text { 4. Динамичность } \\
\text { изображения } \\
\text { согласно } \\
\end{array}$ & $\begin{array}{l}\text { Изображению } \\
\text { полностью } \\
\text { статично } \\
\end{array}$ & $\begin{array}{l}\text { Слабовыраженная } \\
\text { динамичность } \\
\text { изображения }\end{array}$ & $\begin{array}{l}\text { Изображение } \\
\text { отличается хорошей } \\
\text { динамичностью }\end{array}$ \\
\hline
\end{tabular}




\section{НАУКА, ОБЩЕСТВО, КУЛЬТУРА: ПРОБЛЕМЫ \\ И ПЕРСПЕКТИВЫ ВЗАИМОДЕЙСТВИЯ В СОВРЕМЕННОМ МИРЕ}

\begin{tabular}{|c|c|c|c|}
\hline $\begin{array}{l}\text { художественному } \\
\text { замыслу }\end{array}$ & & & \\
\hline \multicolumn{4}{|c|}{ Блок 3. Художественно-выразительные качества цвета } \\
\hline $\begin{array}{l}\text { 1. Живописность } \\
\text { работы }\end{array}$ & $\begin{array}{l}\text { Отсутствует } \\
\text { живописный } \\
\text { подход в работе: } \\
\text { преобладание } \\
\text { локальных цветов; } \\
\text { Цветовая } \\
\text { дисгармония. }\end{array}$ & $\begin{array}{l}\text { В работе не хватает } \\
\text { живописности: } \\
\text { использование } \\
\text { локальных цветов и } \\
\text { 2-3 сложных цвета; } \\
\text { отмечается } \\
\text { небольшая } \\
\text { цветовая } \\
\text { дисгармония. }\end{array}$ & $\begin{array}{l}\text { Работа выполнена } \\
\text { достаточно } \\
\text { живописно; } \\
\text { преобладание } \\
\text { сложных цветов; } \\
\text { цветовая гармония. }\end{array}$ \\
\hline $\begin{array}{l}\text { 2. Соответствие } \\
\text { цветового } \\
\text { решения } \\
\text { художественному } \\
\text { замыслу }\end{array}$ & $\begin{array}{l}\text { Цветовое решение } \\
\text { не соответствует } \\
\text { художественному } \\
\text { замыслу }\end{array}$ & $\begin{array}{l}\text { Цветовое решение } \\
\text { поддерживает } \\
\text { художественный } \\
\text { замысел. }\end{array}$ & $\begin{array}{l}\text { Цветовое решение } \\
\text { соответствует } \\
\text { художественному } \\
\text { замыслу, усиливает } \\
\text { выразительность } \\
\text { художественного } \\
\text { образа. }\end{array}$ \\
\hline
\end{tabular}

Особенностью предлагаемой системы критериев оценки является «весомость» каждого блока в общей (итоговой) оценке». Все блоки расположены «сверху-вниз» в порядке убывания степени их приоритетности. Итоговая оценка будет определяться не как средне-арифметическая, а согласно «весомости» каждого блока. Первый блок является ведущим и самым значимым в общей оценке. В данную систему не включен критерий, оценивающий стремления, старания учащихся, их желание работать на уроке. Но данный критерий существует по умолчанию. И педагог должен его учитывать при выведении общей оценки.

Следует отметить, что представленные критерии являются не просто требованиями к работе учащегося, но и отражают педагогические задачи процесса обучения образному решению портрета учащихся общеобразовательной школы.

Обозначенные критерии оценки детского рисунка представляют собой комплексный анализ изобразительной деятельности детей по исследуемой нами теме, отражают педагогические взгляды на процесс обучения детей изобразительному искусству и позволяют создать благоприятные условия для формирования учащимися яркого, выразительного, индивидуального художественного образа в одном из самых сложных жанров - портрете. 


\section{Список литературы}

1. Вербовская В.С. Эмоциональная отзывчивость: содержание и структура понятия // Вестник Нижневартовского государственного университета. - 2013. - № 4. - С. 74-78.

2. Игнатьев С. Е. Закономерности изобразительной деятельности детей: учебное пособие для вузов / С. Е. Игнатьев. - Москва: Академический Проект, 2020. $-155 \mathrm{c}$.

3. Лыкова Е.С. Критерии оценки детского рисунка // Омский научный вестник. - 2015. - № 4 (141). - С. 177-181.

4. Полынская И.Н. Теория и практика обучения изобразительному искусству в общеобразовательной школе с учетом национально-регионального компонента (на примере ХМАО-Югры): Монография / И.Н. Полынская. Нижневартовск: Изд-во Нижневарт. Гуманит. Ун-та, 2009. - 310 с.

5. Рыбников Н.А. Детские рисунки и их изучение / Н.А. Рыбников. Москва; Ленинград: Гос. изд-во, 1926. - 47, [1] с. 